Maria das Graças Barbosa Moulin¹ Ana Beatryce Tedesco Moraes ${ }^{2}$

\section{Vamos fazer poeira! Fontes e expressões da pressão no trabalho do setor de rochas ornamentais no Espírito Santo*}

\author{
Let's get to work! Causes and effects of pressure at work in \\ ornamental stone sector in Espírito Santo, Brazil
}

\begin{abstract}
Ornamental stone sector in Espirito Santo, Brazil
\end{abstract}
\begin{abstract}
${ }^{1}$ Professora Doutora do Departamento de Psicologia Social e do Desenvolvimento; professora colaboradora do Programa de Pós-Graduação em Psicologia da Universidade Federal do Espírito Santo.

${ }^{2}$ Mestranda em Psicologia Social pela Universidade Federal do Espírito Santo; bolsista da Capes.
\end{abstract}

*Apoio financeiro:

Ministério da Saúde (MS) / Conselho Nacional de Desenvolvimento Científico e Tecnológico (Cnpq), Fundação de Apoio à Ciência e Tecnologia do Espírito Santo (FAPES) - Processo $\mathrm{n}^{\underline{0}}$ 37.234.315.

Contato:

Maria das Graças Barbosa Moulin

Avenida Fernando Ferrari, $\mathrm{s} / \mathrm{n}$, Campus Goiabeiras, Vitória, ES

CEP: 29075-015

E-mail:

mgbmoulin@gmail.com

\section{Resumo}

Este artigo tem por objetivo discutir o trabalho perigoso e penoso no setor de rochas ornamentais e seus efeitos do ponto de vista da saúde mental a partir dos dados obtidos na pesquisa "Homens (d)e pedra: trabalho e saúde na extração e beneficiamento de rochas ornamentais", realizada no estado do Espírito Santo em 2008. O estudo utilizou metodologia qualitativa, possibilitando que os trabalhadores pudessem fazer associações entre seu trabalho e possíveis agravos à saúde. Além das dores pelo corpo, das lombalgias, das alergias, emergiu também o chamado "estresse", tendo como fonte a pressão no trabalho. A partir de um panorama da cultura e da sociabilidade desses trabalhadores, elegemos as categorias de análise entre as fontes da pressão como: as metas, a jornada de trabalho, as relações verticais e as relações horizontais. Esta última foi o contraponto dos efeitos adversos da pressão. Em seguida, discutimos as expressões da pressão, que são os sintomas: insônia, irritabilidade, falta de paciência, submissão e os efeitos sobre a sociabilidade da família. Observamos que os dados sobre sofrimento psíquico expressos pela ideia de "estresse", não identificados em estudos anteriores realizados no setor, começaram a surgir na pesquisa acima citada, tornando-se mais um desafio e uma preocupação para o campo temático da Saúde do Trabalhador.

Palavras-chave: trabalho e saúde mental; trabalho perigoso e penoso; trabalho no setor de rochas.

\begin{abstract}
The purpose of this article is to discuss the dangerous and strenuous work carried out within the ornamental stone sector and its effects from the mental health point of view . It is based on data obtained in the research "Men of/and stone: work and health in ornamental stone extraction and processing", conducted in the state of Espírito Santo, Brazil, in 2008. The qualitative approach allowed workers to make associations between their work and its possible negative effects on their health. Besides allergies and body pain, especially in the lumbar region, stress also came forth as resulting from pressure at work. Considering the panorama of those workers' culture and sociability, we selected the analysis categories among the sources of pressure: goals, workday, vertical and horizontal relationships, this last one being the counterpoise for pressure adverse effects. Then, the expressions of the effect of pressure are discussed: insomnia, irritability, lack of patience, submission, and symptoms related to family life. We observed that the psychological suffering expressed by the idea of "stress", which was not cited in previous studies, first emerged in the research mentioned above, bringing one more challenge and concern to the field of Worker's Health .
\end{abstract}

Keywords: work and mental health; dangerous and strenuous work; work in the ornamental stone sector.
Revisado: 07/06/2010

Aprovado: 01/07/2010 


\section{Introdução}

\section{Trabalho e saúde mental}

O campo da Saúde Mental e Trabalho pode ser considerado uma subárea da Saúde do Trabalhador, herdando desta alguns de seus pressupostos básicos: tomar o trabalho como fato social determinante no processo saúde/doença, reconhecer o saber-fazer dos trabalhadores, considerar a subjetividade dos trabalhadores, levar em conta a participação dos trabalhadores na produção de conhecimentos e na perspectiva de transformação dos processos de trabalho adoecedores.

Trata-se de pensar a Saúde Mental não apenas nos seus aspectos microssociais, a partir da família, principalmente, ou da escola, mas também com base nos processos de trabalho, na interseção do indivíduo com a sociedade (SELIGMANN-SILVA, 1994).

De acordo com Seligmann-Silva (1994), o campo da Saúde Mental e Trabalho é marcado pela contribuição de diferentes disciplinas, entre elas, a Psicologia do Trabalho, a Psicodinâmica do Trabalho, a Psicanálise, a Ergonomia, os Estudos Psicossomáticos, a Psicologia Social, a Organização do Trabalho, a Saúde Ocupacional e a Medicina do Trabalho, a Toxicologia e Neurologia Clínica e a Epidemiologia. Conforme a autora, a despeito dos diversos enfoques e disciplinas relacionados com esse campo, podem-se distinguir três principais correntes associadas ao estudo da Saúde Mental e Trabalho: a primeira inclui teorias sobre o estresse cujos estudos iniciais estavam voltados apenas para os aspectos fisiológicos, mas, posteriormente, levaram em conta fatores sociais, incluindo o trabalho; a segunda é composta por teorias constituídas pela Psicodinâmica do Trabalho, que estuda o sofrimento mental relacionado com o trabalho; e a terceira baseia-se no conceito de desgaste mental formulado pela autora, que pode se constituir em um paradigma integrador das diferentes correntes teóricas, uma vez que:

[...] permite compreender as interações entre os 'fatores' objetivados pelos estudos de work-stress, a subjetividade e diferentes esferas da vida social, a partir dos âmbitos microssociais do local de trabalho e da família, passando pelos intermediários (empresa e comunidade) até os macrossociais sociais (divisão internacional de trabalho, políticas industrial, tecnológica e salarial de cada país) balizando as relações de trabalho em cada realidade. (SELIGMANN-SILVA, 1995, p. 294)

Do ponto de vista acadêmico, a partir da década de 1980, multiplicaram-se os estudos sobre Saúde Mental e Trabalho em diversas categorias (bancários, professores, profissionais da saúde, operadores de telemarketing, entre outras), utilizando-se os diversos aportes teórico-metodológicos.

Na realidade cotidiana dos trabalhadores, a reestruturação produtiva do capital operada a partir dos anos de 1970, expressa pela automatização, pela precarização do trabalho e pelo desemprego estrutural, aliada à globalização e à compressão do tempo-espaço, trouxe não apenas modificações profundas ao mundo do trabalho, mas também às formas de sociabilidade dos trabalhadores e efeitos do ponto de vista da saúde. Parece senso comum hoje "estar estressado". Comentam-se em profusão as dificuldades de sono, a irritabilidade, a gastrite, a falta de memória e até mesmo a falta de sentido de viver. No entanto, na prática, ainda é muito difícil associar essas dores, esses desgostos ao trabalho. Os trabalhadores tendem a vivenciar essas dificuldades como uma fragilidade pessoal e nisso têm o respaldo de toda uma ideologia que insiste em responsabilizá-los por sua empregabilidade, por seu emprego (ou desemprego) e por sua saúde.

Na assistência, conforme estudo de Sato e Bernardo (2005), a maioria das queixas principais que chegavam ao Centro de Referência em Saúde do Trabalhador (CRST) de Campinas ainda estavam relacionadas com sintomas físicos e não com a saúde mental. Na procura por esse serviço:

[...] é insignificante a atribuição, como primeiro diagnóstico, de distúrbio mental; tal realidade se modifica quando se toma a LER como diagnóstico, a qual parece funcionar como uma espécie de fachada para que os problemas de saúde mental sejam levados à assistência [...]. (SATO; BERNARDO, 2005, p. 875)

Além disso, deparamo-nos com outro problema grave: o não reconhecimento do trabalho como causador de problemas psíquicos, o que não indica sua ausência, mas, antes, reflete:

[...] a persistência da dificuldade por parte de todos os envolvidos - empresas, profissionais de saúde e peritos do INSS - em reconhecer o trabalho como causador de problemas de saúde mental, o que, conseqüentemente, reduz a busca de ajuda em serviços de referência, como os CRSTs. (SATO; BERNARDO, 2005, p. 872)

Jardim (2001, p. 139) alerta que, embora se tenha produzido muito conhecimento relacionado com a Saúde Mental e Trabalho:

[...] não dispomos ainda de uma nosologia que integre a dimensão do trabalho e seus equivalentes (emprego, subemprego, desemprego) aos conhecimentos já disponíveis a respeito do processo saúde/doença nos níveis biológico, social e cultural.

A autora ressalta características das classificações psiquiátricas relativas ao trabalho, tais como a redução de suas dimensões histórica, sociológica e política, a noção de trabalho como uma atividade naturalizada, raramente determinante do adoecimento, cujo diagnóstico relativo à doença e ao trabalho é mais comumente utilizado por ocasião dos processos de admissão.

Como podemos notar, a despeito dos avanços que obtivemos nas últimas décadas, seja no reconhecimento de vários agravos à saúde mental relacionados ao trabalho nas leis da previdência, seja no aumento da produção acadêmica, várias são as questões que persistem, como as que apontamos acima. Parece-nos que 
urge continuar nossos estudos na produção de contradiscursos até que possamos, um dia, quem sabe, desfrutar de uma vida e de um trabalho produtores de desejos de mais vida e trabalho e não de sofrimento e doença. Nesse sentido, dando continuidade a essa caminhada, propomos agora analisar a saúde mental em uma categoria ainda pouco estudada, os trabalhadores do setor de rochas ornamentais.

\section{Trabalho no setor de rochas ornamentais}

Este artigo tem por objetivo analisar as repercussões que o trabalho penoso e perigoso pode suscitar em termos da saúde mental dos trabalhadores. Nossa proposta de análise gira em torno do trabalho no setor de rochas ornamentais - extração, beneficiamento e transporte de mármore e granito no Estado do Espírito Santo - e, mais especificamente, trata-se de relato da pesquisa intitulada "Homens (d)e pedra: trabalho e saúde na extração e beneficiamento de rochas ornamentais", cuja análise vem ancorada em uma perspectiva histórica em estudos que empreendemos no setor desde 1999 (MOULIN; WENICHI; REIS, 2003; MOULIN, 2006, 2007a, 2007b, 2008; MOULIN; REIS; WENICHI, 2000, 2001; MOULIN; MINAYO-GOMEZ, 2008).

Os processos de trabalho no setor são bastante diversificados: em geral são executados a céu aberto, na presença de poeiras, produtos químicos, muito ruído; outros são realizados em grandes alturas, ou em desnível de solo, incluem pegar peso, manobras de blocos e chapas e, muitas vezes, tudo isso ocorrendo simultaneamente. Essas são características que qualificam esse trabalho como perigoso e penoso, e a atividade é considerada de grau de risco $4^{3}$, a maior gradação atribuída às atividades listadas na Norma Regulamentadora $\mathrm{n}^{\circ} 4$.

O setor é constituído principalmente por pequenas e médias empresas. Pequena empresa pode significar um proprietário, dois teares e meia dúzia de empregados. O setor comporta também grandes empresas exportadoras, que extraem, beneficiam e exportam suas próprias pedras. O transporte pode ser realizado tanto por motoristas da própria empresa, quanto por motoristas autônomos, como ocorre mais comumente. É bastante comum nas estradas do Espírito Santo se encontrar em blocos caídos, o que acontece até mesmo no perímetro urbano.

Esse rápido quadro do setor já nos dá uma visão da complexidade de situações de trabalho que ali encontramos: empresas clandestinas ao lado de outras bem estruturadas, trabalhadores com carteira assinada ao lado de trabalhadores terceirizados e precarizados, além de nos alertar a respeito da provisoriedade constante dos resultados de nossos estudos e da necessidade de um contínuo aprofundamento em termos de novas pesquisas.
Do ponto de vista da economia, o setor é de grande importância, gera lucros e produz empregos em dois polos definidos: um ao sul, em torno da cidade de Cachoeiro de Itapemirim, e outro ao norte do Estado, em torno da cidade de Nova Venécia. Lucros, geração de empregos e a beleza das pedras é o lado polido do setor. O lado não polido, que é o lado da pedra que não aparece, que é feio e desagradável ao tato, fica por conta dos dez acidentes fatais ocorridos em 2008 ou do acidente que aconteceu recentemente, vitimando um rapaz de 21 anos. ${ }^{4}$ No lado avesso da pedra, ficam os corpos mutilados, o lamento das viúvas, os braços e as pernas doloridos, as lombalgias, as alergias e, mais recentemente, a insônia, a falta de paciência, enfim, o "estresse".

Em nossa primeira incursão ao campo, tínhamos inteira convicção da associação entre esse tipo de processo de trabalho e os agravos à saúde. Mas os trabalhadores eram unânimes em negar agravos à saúde, ainda que muitos deles tivessem deficiência auditiva, certamente fruto da convivência cotidiana com ruídos no trabalho. Aprendemos, então, que saúde para aquela população é poder trabalhar. O uso do corpo como instrumento deixava claro que agravo à saúde significava estar suficientemente doente ou fraco, obrigando o trabalhador a faltar ao trabalho. Então, ter saúde significava ter "força”, ter "disposição" para o trabalho (MOULIN; REIS; WENICHI, 2000, 2001).

Nesse contexto, o trabalho apresentava-se, em primeiro lugar, como meio de sobrevivência, em segundo, como uma atividade natural do "ser homem" e, finalmente, como espaço social de trocas positivas com colegas. Ou seja, a atividade de trabalho tinha valoração tanto do ponto de vista da sobrevivência material, quanto simbólica daquelas pessoas.

\section{Saúde, sociabilidade e cultura}

Esta discussão introdutória sobre trabalho e saúde em estudo realizado com os trabalhadores do setor de rochas já nos dá algumas pistas sobre a cultura e a sociabilidade dessa população. O trabalho e a saúde são englobados e vivenciados como um valor - confere o estatuto da natureza de "ser homem", no qual a marca de virilidade e masculinidade implica trabalhar com disposição, sem medo, sem esmorecer. Isso é ser bom trabalhador.

Em estudo posterior, aprofundamos nossa análise sobre as marcas da cultura nessa população e pudemos observar que a importância atribuída ao trabalho estava fortemente associada à importância conferida ao grupo familiar. Então, ser um homem honrado era ser um bom trabalhador e um bom pai de família (não se pode ser um bom pai de família sem ser um trabalhador). Este

\footnotetext{
${ }^{3}$ A gradação do risco da atividade principal de uma empresa regida pela CLT é realizada pelos Serviços Especializados em Engenharia de Segurança e em Medicina do Trabalho pela Norma Regulamentadora noำ, aprovada pela Portaria MTb ํㅜ 3.214, de 8 de junho de 1978.

${ }^{4}$ Jovem morreu vítima de acidente de trabalho em um distrito de Cachoeiro de Itapemirim quando uma chapa de granito caiu por cima dele ao carregar um caminhão, de acordo com gazetaonline. Disponível em: < http://gazetaonline.globo.com/_conteudo/2010/01/593824-jovem + morr e+em+acidente+ no+trabalho.html >. Acesso em: 25 jan. 2010.
} 
estudo realizado no sul do Estado observou também a importância da comunidade (rede de vizinhos e parentela) para a sociabilidade local (MOULIN, 2006).

As pequenas comunidades, como Itaoca, Gironda ou Soturno (distritos de Cachoeiro de Itapemirim, ES), têm sua população masculina majoritariamente empregada no setor de rochas, praticamente única opção de trabalho da região. Vamos, então, vislumbrando o quadro social: o trabalho que provoca acidentes e agravos à saúde é o mesmo que ordena socialmente toda uma população e que forja esperanças para projetos futuros. Um jovem que se insere em um emprego no setor de rochas vislumbra a possibilidade de ingresso na vida adulta, adquirindo alguns bens, pagando suas contas cotidianas, formando uma família e criando seus filhos. Torna-se o paradigma do homem honrado - trabalhador e pai de família.

Ao trabalho, à família e à comunidade vem associarse uma forte religiosidade entre essa população trabalhadora, formando uma visão de mundo que norteará suas condutas sociais. A religiosidade exerce uma dupla função psicológica: por um lado, reforça a defesa psíquica contra o enfrentamento dos riscos (que muitos entregavam a Deus) e dificulta uma transformação da atividade para um trabalho com mais segurança; por outro lado, quando ocorre um acidente fatal ou mutilador, as viúvas se consolam e, ao mesmo tempo, se fortalecem na religião para enfrentar as adversidades. No estudo de Moulin (2006, p. 101):

Todas as entrevistadas mencionaram a religiosidade e a fé como um suporte simbólico para agüentar a notícia do acidente e suas conseqüências. É a primeira lembrança quando se referem às forças de que necessitaram para superar o acidente: 'Primeiro Deus, que é a força maior, vem de Deus [...]'. Quase todas as frases das mulheres foram entremeadas com as expressões 'se Deus quiser', 'Graças a Deus', 'esperando no Senhor', 'a justiça de Deus' e outras tantas variantes.

Do ponto de vista do trabalho, o medo de perder o emprego pode superar o medo de perder a vida. Perder o emprego significa perder o meio de sobrevivência material e simbólica. Nesse sentido, minimiza-se o risco como uma defesa psíquica que permite ao trabalhador retornar cotidianamente a um processo de trabalho que tem risco de morte.

É interessante assinalar que os entrevistados comentavam que o trabalho rude, pesado, "não era para qualquer um”. Aqui, a valoração da virilidade transforma um trabalho penoso e perigoso em um meio de provar a masculinidade, a coragem e a disposição - uma característica desfavorável do processo de trabalho que possibilita ao trabalhador um meio de identificação positiva. Trata-se de um arranjo delicado, prestes a desmoronar, conforme Moulin (2006, p. 120):
Em outro caso, o trabalhador chegou a avisar ao encarregado do perigo de deslizamento de pedras, mas o encarregado insistiu: 'Vai embaixo daquilo ali pra limpar' e, ao ouvir do empregado sobre o perigo, o encarregado apela, segundo a viúva: 'Perguntou se ele não era homem. Porque ele estava com medo de entrar ali embaixo, e depois, com poucos dias aconteceu'. O apelo à virilidade submete o trabalhador. São as 'mortes anunciadas'.

Esses arranjos psíquicos dão aos trabalhadores e às suas famílias um suporte simbólico em que as contradições e os paradoxos não se excluem, como disse Moulin (2006, p. 103):

Para continuarem mantendo certo ordenamento entre o ideal cultural (de valoração do trabalho, do provimento e desenvolvimento da família, do sentimento de pertencimento a uma localidade, de bom cristão), e a realidade (desemprego, trabalhos precários, riscos, acidentes, dificuldades em manter a família), muitos moradores procedem a um ordenamento da vida cotidiana, em que juntos caminham o trabalho e a morte, a família disciplinada e a tragédia, a localidade de pedra e o orgulho pela localidade justamente por causa das pedras. Retiram a força e a esperança do sobrenatural, do 'outro mundo’ e vão superando os obstáculos um a um.

A partir desse panorama, podemos vislumbrar a cultura, os valores e o modo como essa população organiza simbolicamente as questões do trabalho e da saúde e como esses arranjos podem produzir força e disposição, bem como resignação. Estamos aqui enunciando a produção de sentidos.

\section{A pesquisa}

A pesquisa "Homens (d)e pedra: trabalho e saúde na extração e beneficiamento de rochas ornamentais", ${ }^{5}$ cujos resultados apresentamos aqui, não tratou das associações específicas entre trabalho e saúde mental, embora, em seus resultados, essas associações tenham emergido em profusão. Tal pesquisa foi realizada no ano de 2008 em três municípios do Espírito Santo. Seus objetivos iniciais foram: evidenciar aspectos na organização e nas condições de trabalho que constituam riscos à saúde dos trabalhadores; descrever os agravos à saúde dos trabalhadores, efeito da atividade que exercem; e evidenciar os efeitos da atividade de trabalho sobre a vida familiar e a vida social dos trabalhadores. Como já tínhamos experiência anterior com os trabalhadores desse setor que produziam um sentido próprio sobre a associação entre trabalho e saúde, em que o agravo à saúde só é considerado quando já se tornou uma doença, optamos por uma metodologia qualitativa e mediada por desenhos e discussão sobre trabalho, saúde e vida.

\footnotetext{
${ }^{5}$ Essa pesquisa foi aprovada por Comitê de Ética filiado ao Conselho Nacional de Saúde em 25/09/2007 e cumpriu os requisitos previstos na Resolução 196/1996 do Conselho Nacional de Saúde.
} 


\section{Metodologia}

Entendendo a relevância da participação e do saber-fazer dos trabalhadores na produção de conhecimentos e soluções para a área do trabalho e saúde, saímos a campo inspirados pelo "mapeamento", metodologia proposta pela Rede Projeto Vida Viva. ${ }^{6} \mathrm{O}$ Mapping tem como objetivo possibilitar aos trabalhadores a análise do trabalho que executam, estabelecendo conexões entre este e os fatores relacionados com agravos à saúde pela mediação de desenhos produzidos pelos próprios trabalhadores. $\mathrm{O}$ mapeamento é realizado em quatro etapas: desenho do "Mapa do Corpo"; "Mapa do Local do Trabalho"; "Mapa Nosso Mundo"; e "Plano de Ações".

Em função do limite de tempo e das dificuldades de acesso aos trabalhadores, restringimos nosso trabalho ao "Mapa do Corpo" e ao "Mapa do Local do Trabalho". A equipe de pesquisa levou pronto o desenho de um corpo humano e os trabalhadores assinalaram e desenharam nele o que os incomodava a partir do processo de trabalho. Depois, eles mesmos desenharam o local de trabalho e explicaram a relação deste com o desenho do corpo. Com essa metodologia mais participativa, tínhamos a intenção de superar a formalidade das entrevistas.

Dessa forma, realizamos três incursões ao campo. A primeira foi à cidade de Cachoeiro de Itapemirim (ES), em um evento de saúde promovido pelo Sindicato dos Trabalhadores em Indústria de Extração e Beneficiamento do Mármore, Granito e Calcário do Espírito Santo (Sindimármore). Este grupo contou com a participação de apenas cinco trabalhadores entrevistados. A segunda incursão foi com um grupo de quinze trabalhadores de uma empresa (beneficiamento) na localidade de Governador Lindenberg. Essa empresa se encontrava paralisada em função de irregularidades, e os trabalhadores estavam disponíveis para participar da pesquisa. A atividade teve duração de cerca de três horas. A terceira incursão foi a uma empresa de ponta em termos de tecnologia (de extração e beneficiamento) em Aracruz, em funcionamento, que liberou grupos de trabalhadores para que procedêssemos ao mapeamento. Nesta empresa, foram constituídos dois grupos de seis trabalhadores com duração de uma hora e meia cada um. O fato de a empresa estar em pleno funcionamento limitou o tempo de que dispúnhamos para discussão. Todo o trabalho foi gravado em vídeo e em gravador digital e, posteriormente, transcrito. A pesquisa foi submetida e aprovada pelo comitê de ética em pesquisa da Escola Superior de Ciências da Santa Casa de Misericórdia de Vitória.

\section{Resultados e discussão}

Por se tratar de um processo de trabalho que requer força física e utilização do corpo como um instrumento de trabalho, não foi de espantar que emergissem associações de agravos de saúde ao corpo relacionadas às condições físicas do trabalho. As lombalgias, as alergias, as dores nos braços, nos joelhos e nos pés, dores de cabeça e na nuca - todas essas dores emergiram no Mapa do Corpo associadas a más posturas, aos desníveis do solo, ao calor, ao ruído e aos produtos químicos. Mas, para efeito da nossa discussão sobre saúde mental, vamos nos ater à nuvem que desenharam acima da cabeça do Mapa do Corpo. Dentro dessa nuvem, os trabalhadores escreveram "estresse”, "pressão" e "chefia”. Foi uma surpresa encontrar, pela primeira vez, entre os estudos que realizamos com a categoria de trabalhadores do mármore e granito, relatos de sofrimento psíquico, trazendo mais uma preocupação para o campo temático e para os estudiosos da Saúde do Trabalhador.

As queixas advêm do que os trabalhadores chamaram de "pressão do trabalho". Eles se referiam a essa pressão de duas formas: uma relacionada com suas "fontes"; e outra, com as suas "expressões", ou seja, ela pode ser causada por diferentes fatores e é geradora de sintomas físicos e psíquicos.

A pressão tem uma "fonte" principal no trabalho, seja do chefe, seja das metas, seja da produção. A pressão advém do modo de produção capitalista que tem como finalidade primeira o lucro, mesmo que a saúde ou a vida dos trabalhadores estejam em risco. As suas "expressões" constituem-se em agravos à saúde física e psíquica, além dos efeitos na sociabilidade dos trabalhadores.

Nessa perspectiva, elegemos quatro categorias de análise relacionadas com a organização do trabalho em que a pressão tem origem e que geram suas expressões: a) as metas; b) a jornada; c) as relações horizontais e d) as relações verticais. Em seguida elencamos as expressões da pressão que foram mais frequentemente citadas em contexto.

A organização do trabalho pode estar relacionada, segundo Dejours, Abdoucheli e Jayet (2009), com a possibilidade de se ter um trabalho fonte de equilíbrio quando os trabalhadores têm a oportunidade de dar sua contribuição criativa no trabalho e quando podem regular suas necessidades físicas e psíquicas com as necessidades advindas do processo de trabalho. A organização do trabalho pode também ser fonte de sofrimento psíquico quando o trabalhador se vê refém de uma atividade na qual ele não pode, ou dificilmente poderá intervir criativamente.

\section{Metas}

As chamadas metas de produção, quase sempre inatingíveis e com curto prazo para serem alcançadas, são eleitas de forma alheia à realidade dos trabalhadores e, evidentemente, sem a sua participação. São também hoje a mais sofisticada forma de controle não só dos comportamentos, mas da subjetividade dos que vivem do trabalho. As metas, coroadas de um discurso de competitividade, de excelência, de concorrência, em um contexto de desemprego estrutural, exigem que os trabalhadores

${ }^{6}$ Disponível em: <http://www.projetovidaviva.com>. 
superem continuamente seus limites físicos e psíquicos - e, muitas vezes, essa "superação" resulta em rupturas desses mesmos limites. Os trabalhadores têm dificuldade em definir seus limites e recusar tarefas que os ultrapassem, sobretudo no contexto de desemprego.

Especialmente porque se vive em uma situação socialmente compartilhada em que parece senso comum o fato de que "ninguém tem tempo", "todo mundo está estressado", "a vida está uma correria”, há, certamente, uma naturalização de uma sociabilidade "estressada". Para Sennett (2006, p. 13), a forma de vivenciar o tempo é um dos desafios a ser enfrentado por aqueles que são capazes de prosperar em sociedades instáveis e fragmentadas no que se refere à forma de:

[...] cuidar de relações de curto prazo, e de si mesmo, e ao mesmo tempo estar sempre migrando de uma tarefa para outra, de um emprego para outro, de um lugar para outro.

Como destaca o autor, "Desde a época de Marx, a instabilidade pode parecer a única constante do capitalismo" (SENNETT, 2006, p. 23).

A maioria das ocupações, como bancários, operadores de telemarketing, professores, profissionais da saúde, vivem sob a pressão das metas. Sennett (2006, p. 53), referindo-se à competição entre equipes nas empresas, chama a atenção para o sistema de recompensas denominadas por Robert Frank de "tudo-ou-nada”, em que os prêmios são destinados apenas à equipe vencedora, o que "[...] gera alto nível de estresse e ansiedade entre os trabalhadores" na medida em que os esforços daqueles que "quase" alcançaram as metas não são computados ou reconhecidos. Pois bem, a ideologia das metas chegou ao interior, às empresas de extração e beneficiamento de mármore e granito.

A meta é uma fonte da chamada "pressão". A pressão produzida pelas metas é traduzida pelas expressões: "O patrão está em cima”, "Tem que dar produção”, "Eles só querem o quê? Produção. Eles veem o funcionário como uma máquina, uma máquina de produzir". A pressão pelas metas não fica circunscrita à jornada, como se constata nesta fala: "[...] eu vou citar um exemplo, com licença, aí: eu tô de férias, né? Meu telefone tocou e de onde veio? [risadas de todos]”. Todos já sabiam que, mesmo de férias, ainda que de madrugada, os trabalhadores são chamados quando há necessidade da produção. Esse estado permanente de prontidão e ritmo de trabalho acelerado diminui a autonomia dos trabalhadores de gerir seu tempo, suas escolhas e sua vida.

Esta questão está bem ilustrada nas falas de dois trabalhadores: “[...] se não produzir, você não recebe. É aquela pressão, aí vai ter que demitir, e não sei o quê. Ah, é muita conversa. É muita pressão psicológica” e:

[...] vocês vão ouvir muito isso, que se chama 'tem que produzir'. Essa é uma palavra que não sai da boca do patrão e do encarregado. 'Tem que produzir', 'Tem que produzir'. Eles falam que tem que produzir 1.000 metros de pedra: a gente produz 1.000 metros. Mês que vem, você tem que produ- zir 1.200 metros. Aí, daqui um pouquinho, você produz 3.000 metros e não tá bom pra eles, com a mesma quantidade de funcionários. Então tem essa palavra 'Tem que produzir'.

\section{Jornada de trabalho}

As metas vão certamente ditar o andamento da jornada de trabalho que diz respeito à estrutura temporal em que o trabalhador é contratado e também está relacionada com as pausas para descanso e alimentação. Ainda que tenham uma jornada de trabalho prescrita, essa é ditada pelas metas e pela produção. Então, na prática, nem sempre se tem hora para chegar e para sair. Eles expressam a jornada como "na hora que chama tem que ir". Os trabalhadores têm dificuldade em recusar a execução de uma atividade, conforme se expressou um participante:

[...] às vezes a gente enfrentamos porque precisamos. Muitos aqui sabem, se escalou eu, ele, vamos supor, pra trabalhar até tal hora da noite, se eu estou escalado quem sou eu pra dizer não?

São situações sobre as quais o trabalhador não tem autonomia para recusar. A recusa pode criar uma situação desfavorável e pode significar a demissão em última instância.

Além da prontidão para o trabalho a qualquer tempo, os trabalhadores enfrentam, no seu cotidiano, o ritmo acelerado de trabalho. Segundo os participantes, para tudo há pressa. As metas são de grande produtividade e se tem pouco tempo para cumpri-las. Essa situação se expressa na fala do seguinte participante: "Quer me estressar? Marca um serviço pra mim e me bota pressa [...]. Se eu sei fazer, eu sei fazer, eu vou fazer. Agora, se me botar pressa, pressão, aí eu me arrebento”.

Além de provocar o "estresse”, a pressa e a pressão potencializam os riscos do trabalho, conforme o mesmo participante esclareceu:

Aí, pronto, aí é a hora em que você pode cair de um andaime. Você teria que fazer um andaime bem feito, você já não pode fazer, entendeu? [...]. Ele não aceita que ali você tem que gastar 20,30 minutos, uma hora pra você fazer um andaime pra, depois, trabalhar seguro. Ele não concorda. E isso e a pressão já tá vindo em cima dele, lá dos patrões, tá vindo de lá, entendeu?

Sem controle sobre a gestão do seu tempo, trabalhando em ritmo intenso, as consequências aparecem com muita clareza, como indica este discurso:

Eu vejo assim, o cansaço físico às vezes você contorna, eu trabalhei durante muitos anos no meio agrícola, então você chega em casa cansado, você deita, você relaxa e, no fim do dia, você tá pronto.

É interessante a diferenciação que esse trabalhador faz da qualidade do cansaço. Para o cansaço dos dias que correm, parece não haver descanso. Ainda conforme o mesmo participante: "Agora você chega em casa muito estressado, aí vêm as consequências sérias depois, você não consegue relaxar, é a insônia que surge”. 
E mais uma vez emerge a preocupação com os riscos do trabalho:

[...] você sente dificuldade muitas vezes no raciocínio rápido, até pra própria defesa dentro do ambiente de trabalho, né? Aí ele vai tá diante de uma situação de perigo e pra ele vai tá tudo normal, ele nem taí, se ligando pra situação.

O perigo surge não só para o equilíbrio psíquico (insônia e suas consequências), como também na execução da atividade de trabalho, pois o cansaço produz desatenção. Além disso, nesse tipo de jornada de trabalho, os membros da família, da mesma forma, também se veem subtraídos de uma convivência mais regular com o trabalhador.

\section{Relações sociais horizontais}

As relações horizontais emergiram como um dos pontos positivos no processo de trabalho. Alguns concordaram que "é a única coisa boa". As relações sociais entre colegas que se constituem de forma solidária e cooperativa são, de fato, segundo Dejours, Abdoucheli e Jayet (2009), uma contribuição positiva para a saúde e o equilíbrio psíquico dos trabalhadores. A partir da possibilidade de poder contar com os companheiros de trabalho em momentos de perigo ou até mesmo para a resolução de problemas cotidianos, o trabalhador exerce seu sentimento de pertença a um grupo, fortalece sua identidade social a partir da interação e do reconhecimento de seus colegas.

As brincadeiras entre os colegas também ajudam a amenizar o estresse, conforme conta um trabalhador: "[...] isso aqui vira uma turma de irmãos, pra tirar um pouco do estresse”.

Infelizmente, os processos de trabalho contemporâneos (LIMA, 1996), embora recomendem o trabalho em equipe, têm como paradigma a competitividade e a concorrência entre os trabalhadores para a obtenção das metas, podendo retirar do cotidiano do trabalhador essa convivência, aqui relatada, de companheirismo e solidariedade. Em estudo anterior, os trabalhadores ressaltaram a amizade entre eles até mesmo como uma condição de segurança no trabalho:

Na área do mármore, na pedreira aqui, companheiro de serviço não pode ter nenhum tipo de problema um com outro [...], se o cara tiver em perigo, e o outro não tá se dando com ele, não vai avisar. Alguma coisa tem que passar por cima daquilo, o cara hoje tá sem jeito com o outro, amanhã tem que tá tranquilo, senão não funciona, tem que tá tudo bem, igual irmão mesmo. (MOULIN; REIS; WENICHI, 2000/2001, p. 53)

\section{Relações sociais verticais}

As relações entre trabalhadores e chefia foi um ponto bastante citado nas discussões com os trabalhadores, uma vez que a pressão, a pressa, a jornada interminável, todos esses pontos negativos advêm do que eles chamam "do patrão", como revelam as falas dos trabalhadores: "É. Fora o que o patrão cobra, né? [...]. E ele cobra. Vamos fazer poeira, é assim mesmo que eles falam: vamos fazer poeira”, e ainda:

\begin{abstract}
Porque em todo o serviço, às vezes, o patrão, às vezes, exige muito, né? Da produção e do serviço e tal [...]. Tem que ter muita eficiência no que está fazendo, se vai plumar umas lâminas tem que plumar certinho, se vai bater chaveta tem que espichar a lâmina bem. De qualquer forma, o patrão tá sempre ali [...]. Ele tá fazendo o dever dele, né? Porque patrão ele quer produção, né?
\end{abstract}

No que se refere à jornada, por exemplo, eles não podem recusar serviços extras (de última hora), como apontam os trabalhadores: "Às vezes a gente é obrigado a fazer sem querer [...] e [...] você tem que cumprir com aquilo que eles determinam ou então você simplesmente tá descartado”.

Um ponto negativo evidenciado é que o saber-fazer dos trabalhadores é constantemente desconsiderado, conforme este discurso: "Eles não aceitam muito não, quando a gente fala qualquer coisa, é aquilo que eles querem. Tá determinado e acabou. Eles não têm hábito de ouvir opinião, sugestão".

O processo de trabalho, seja na extração, seja no beneficiamento, é permeado por variabilidades, por imprevistos. Esses imprevistos são contornados pelo saber dos trabalhadores. Nesse sentido, podemos afirmar, sem medo de errar, que desconsiderar a opinião e o saber do trabalhador constitui, nesse setor, um fator de risco tão grave quanto um caminhão sem freios ou um cabo de aço prestes a arrebentar, como relata um participante:

O mais interessante que eu vejo é que você é um profissional; eles não ouvem a parte profissional. Eles [patrões] acham que sabem tudo e, muitas vezes, eles não têm conhecimento nenhum da área. E não querem ouvir [...]. Eles acham assim, que é da forma deles e acabou [...]. Eles não ouvem o profissional, falou que é mais barato pra eles tá bom.

\section{Expressões da pressão: efeitos na saúde física e psíquica}

Elencamos algumas fontes da pressão e partimos agora para as suas expressões, ou seja, os efeitos das pressões do ponto de vista da saúde e da sociabilidade. É importante ressaltar que se trata de dois lados da mesma moeda, estando, dessa forma, separados por uma questão didática.

Os trabalhadores condensam na expressão "estresse" muitos de seus sofrimentos: a insônia, a falta de paciência com a esposa e os filhos, a impotência em face de atividades que o corpo não aguenta mais executar, a raiva, o cansaço e o desânimo. As alergias e as dores pelo corpo também provocam o chamado "estresse".

Conforme depoimentos: "[...] tem que ter muita disposição, né? A mente tem que estar boa, o corpo tem que estar bem no começo da jornada, pra poder aguentar até o fim do dia, né?”. No final da jornada, a fadiga e o "estresse" se potencializam e se expressam desta forma: “[...] a mente já não aguenta mais, o corpo já não aguenta, já tá tudo doendo”. 
Algumas condições físicas advindas do ambiente do trabalho também provocam estresse: “[...] mais é barulho, né? Porque é dois martelo, né? Eu até uso os dois protetor [auricular], mas a cabeça ainda chega a pocar de tanto barulho", o que confirma outro trabalhador:

O que me preocupa é o estresse, também, e provoca também dor de cabeça pelo barulho. Esses dias eu tava lá, né? Tem vezes em que não dói. Durante a semana dói. Principalmente à tarde, dói demais da conta. Aí tenho que tomar remédio. Barulho e estresse.

Pela primeira vez, ouvimos relatos de depressão entre os trabalhadores do setor: "[...] o nosso encarregado lá, o fulano, ele se afastou que ele tava com depressão [todos ajudam a lembrar]". No entanto, ter depressão foi causa de estranhamento, em primeiro lugar, pelo patrão: “[...] aí o patrão foi e falou com ele bem assim que aquilo dali, como é que foi? Tipo assim, esse negócio é negócio de fresco [risadas]. Que magoou o cara, ainda, né? [...]”. Mas os próprios trabalhadores encararam a questão com ressalvas:

[...] aí eu pergunto pra vocês: o encarregado, o qual administra nós, com problema de crise de depressão, como é que um homem desses vai lidar comigo? Lidar com ele aqui? É botar todo mundo em depressão lá dentro.

Os trabalhadores não tiveram reservas em discutir o estresse. O senso comum em torno da ideia do estresse parece facilitar o debate, há até valorização sobre a pessoa que "resiste" bem ao estresse. Mas o diagnóstico de depressão parece afetar a virilidade dos trabalhadores. Tal diagnóstico adverte: não é todo mundo que aguenta. Então simplifica rotular o colega de fresco. Além do mais, conforme o trabalhador:

[...] se você for reclamar com o patrão, vai acontecer a mesma coisa que disseram aqui que aconteceu com o menino que tava com depressão. $\mathrm{O}$ que que o patrão falou? Que é frescura, negócio de depressão é frescura. Com nós vai falar a mesma coisa, que é frescura.

Além dos efeitos sobre a saúde do trabalhador, essas pressões têm também efeitos sobre a sociabilidade que se expressam da seguinte forma na família: falta de tempo para dedicar-se à família; sentimento de dever (dívida) por ter que estar sempre disponível para a empresa, prejudicando programas em família; falta de paciência e irritabilidade advinda do trabalho, que se traduz em conflitos com membros da família.

É bastante comum que as famílias não saibam dos problemas que os trabalhadores estão enfrentando no trabalho e tendem a imaginar que uma conduta irritadiça por parte do trabalhador seja causada por desamor ou desatenção à família. Conforme a fala de participante:

É uma pressão psicológica muito grande que a gente acaba influenciando no relacionamento da gente. A gente chega em casa, a gente chega da empresa estressado, aí a gente acaba, se tem um probleminha familiar a gente já não tá com a cabeça pronta [...].
Segundo os discursos dos trabalhadores, a partir dessa realidade, eles mesmos se cobram, de maneira que essas pressões são intensificadas pelos próprios trabalhadores, que se sentem subjetivamente obrigados a aceitar a pressão do trabalho, como as horas extras para melhorar o salário, para não esmorecer. Ao mesmo tempo tentam, ainda que reconhecendo que falham, dedicar o tempo que estão fora do trabalho à família. Nas palavras de um trabalhador:

Eu falei: Você sabe pra que que nós estamos fazendo duas horas extras aí no sábado? Ou no meio da semana? Não é porque o corpo está pedindo não, é pra melhorar o salário no final do mês. Aí tem uma outra parte, a gente faz esse sacrifício, e na hora de ser onerado, é ainda penalizado ainda [...] eu falei com minha esposa que nem brigar a gente não briga mais, porque não dá tempo. Ela mesmo fala que acabou as brigas, chega em casa, é banho, janta, o carpete tá lá, as almofadas, a televisão tá ligada, mas é só mesmo pra acabar de desligar e pum. Aí é ela e o filho cutucando: "Pai vamos dormir".

Como exemplo, ainda, um deles citou o gosto pela pescaria, mas se trata de um divertimento que exclui a família, então ele procura evitar.

\section{Conclusão}

O trabalho "bruto", extrativo, de natureza distinta de outras ocupações industriais típicas ou de serviços, pode nos dar a ideia (errônea) da utilização exclusivamente da força física, como uma máquina. O que esta pesquisa mostrou com acuidade é que essa máquina pensa, ama, sofre, se desgasta emocionalmente e se deprime, enfim, ela se "estressa”.

Os trabalhadores revelam que a atividade extrativa é um trabalho diferenciado, que tem suas especificidades, é perigoso e penoso e, além disso, vem adquirindo aspectos globalizados, encontrados em qualquer trabalho urbano, com trabalhadores submetidos à pressa, à pressão e à exploração da subjetividade, ao medo de ser demitido ou de ficar "marcado". Ou seja, aos aspectos da condição de trabalho que torna essa atividade penosa e perigosa (o ruído, as poeiras, os produtos químicos, o trabalho a céu aberto) se agregam elementos atuais da organização do trabalho, como as metas elevadas, a intensificação do ritmo do trabalho, a produção da competitividade entre trabalhadores, o que pode tornar essa atividade ainda mais perigosa.

Merece destaque o fato de que o chamado "estresse" produz desatenção e esta coloca os trabalhadores em risco. Outro destaque vai para a desconsideração insistente que o "patrão", ou a gerência, ou o encarregado tem pelo saber-fazer dos trabalhadores. Essa desconsideração produz riscos à saúde e à vida dos trabalhadores, uma vez que os trabalhadores estão aptos a detectar as variabilidades no processo de trabalho que podem levar a um infortúnio, mas regularmente não são ouvidos. 
Os agravos psíquicos apontados pelos trabalhadores referem-se a problemas cotidianos que não se traduzem em quadros de transtornos psíquicos ou de doenças estabelecidas, mas são os "sintomas menores", como insônia, irritabilidade e falta de paciência. Tais sintomas, chamados menores ou difusos, nem por isso trazem menos sofrimento e consequências psicossociais. Pudemos observar, ainda, que um diagnóstico um pouco mais grave, como o de depressão, pode causar estranhamento entre os trabalhadores na medida em que coloca em xeque a "força" e a "disposição" dos homens.

A emergência do sofrimento psíquico em estudo realizado em um tipo de trabalho reconhecidamente perigoso e penoso, em que já se espera (de forma na- turalizada) dores das mais diversas, acidentes e incidentes, merece atenção por parte dos profissionais da saúde, daqueles que gerenciam o trabalho, do Poder Público e dos representantes dos trabalhadores. O que está em jogo é a vida dos trabalhadores. Sentir sono e desânimo em uma atividade que já é perigosa pode ser fatal. É uma sinalização evidente de que, nessa atividade (como em tantas outras), não se pode "botar pressa"; o que é urgente é a necessidade de transformação da organização do trabalho.

A pressa e a pressão devem estar submetidas à construção de um trabalho que promova a vida e a saúde, o gosto e os desejos. Para o mais, como bem defende Lafargue (1999), temos o direito à preguiça. Temos?

\section{Contribuição de autoria}

Moulin, M. G. B.: desenvolveu o delineamento, o levantamento, a análise e interpretação, a elaboração e a revisão do manuscrito e a aprovação final da versão publicada. Moraes, A. B. T.: contribuiu na elaboração e revisão do manuscrito e na aprovação final da versão publicada.

\section{Referências}

DEJOURS, C.; ABDOUCHELI, E.; JAYET, C. (Org.). Psicodinâmica do trabalho: contribuições da escola dejouriana à análise da relação prazer, sofrimento e trabalho. São Paulo: Atlas, 2009.

JARDIM, S. R. Trabalho e doença mental. In: BORGES, L. H.; MOULIN, M. G. B.; ARAÚJO, M. D. (Org.). Organização do trabalho e saúde: múltiplas relações. Vitória: EDUFES, 2001. p. 137-156.

LAFARGUE, P. $O$ direito à preguiça. São Paulo: Hucitec: Unesp, 1999.

LIMA, M. E. A. Os equívocos da excelência: as novas formas de sedução na empresa. Petrópolis, Rio de Janeiro: Vozes, 1996.

MOULIN, M. G. B. O lado não polido do mármore e granito: a produção social dos acidentes de trabalho e suas conseqüências no setor de rochas ornamentais no sul do Estado do Espírito Santo. 2006. 135 f. Tese (Doutorado em Saúde Pública)-Fundação Oswlado Cruz, Escola Nacional de Saúde Pública Sérgio Arouca, Rio de Janeiro, 2006.

. Acidentes de trabalho o setor de rochas:

estudo de um caso. Cadernos IPUB: Psicopatologia e trabalho: pesquisa, ensino e assistência, v. 13, n. 23, p. 31-45, 2007a.

. De heróis e de mártires: visões de mundo e acidentes de trabalho no setor de rochas ornamentais. Cadernos de Psicologia Social do Trabalho, v. 10, n. 1, p. 37-53, 2007b.
. Desafios para a saúde do trabalhador: vida e morte nas pedreiras de mármore. In: ROSA, E. M.; SOUZA, L.; AVELLAR, L. Z. (Org.). Psicologia social: temas em debate. Vitória: UFES: ABRAPSO, 2008. p. 153-165.

MOULIN, M. G. B.; REIS, C. T.; WENICHI, G. H. Homens de pedra? Pesquisando o processo de trabalho e saúde na extração e no beneficiamento do mármore: relato de uma experiência. Cadernos de Psicologia Social do Trabalho, v. 3/4, p. 47-63, 2000/2001.

MOULIN, M. G. B.; MINAYO-GOMEZ, C. Pedras sobre vidas: vítimas e viúvas na indústria de mármore em Itaoca (ES). Ciência e Saúde Coletiva, v. 13, n. 4, p. 1.361-1.369, 2008.

MOULIN, M. G. B.; WENICHI, G. H.; REIS, C. T. Homens de mármore, saúde de pedra. In: TRINDADE, Z. A; ANDRADE, A. N. (Org.). Psicologia e saúde: um campo em construção. São Paulo: Casa do Psicólogo, 2003. p. 179-194.

SATO, L.; BERNARDO, M. H. Saúde mental e trabalho: os problemas que persistem. Ciência e Saúde Coletiva, v. 10, n. 4, p. 869-878, 2005.

SELIGMANN-SILVA, E. Desgaste mental no trabalho dominado. Rio de Janeiro: Editora UFRJ; São Paulo: Cortez, 1994.

Psicopatologia e psicodinâmica do trabalho. In: MENDES, R. (Org.). Patologia do trabalho. Rio de Janeiro: Atheneu, 1995.

SENNETT, R. A cultura do novo capitalismo. São Paulo: Record, 2006. 